\title{
Breakage of cyanobacterial filaments by small- and large- sized Daphnia: are there any temperature-dependent differences?
}

\author{
Anna Sikora $\cdot$ Piotr Dawidowicz
}

Received: 22 December 2014/Revised: 5 August 2015/Accepted: 10 August 2015/Published online: 2 September 2015

(C) The Author(s) 2015. This article is published with open access at Springerlink.com

\begin{abstract}
Filamentous cyanobacteria disturb food collection in Daphnia by mechanical interference with the filtering apparatus by the long trichomes. The intensity of this interference depends on the water temperature and the Daphnia body size. However, Daphnia are capable of breaking down the filaments, therefore improving the palatability of the cyanobacteria. The main objective of this study was to test whether the shortening of cyanobacterial filaments and the ensuing clearance rate of Daphnia would increase at higher temperatures to a greater degree in small-bodied Daphnia species than in large-bodied one. Laboratory feeding experiments were conducted in order to measure variation in the length of Cylindrospermopsis raciborskii trichomes and to calculate clearance rate. The filament length and the cyanobacteria clearance rate by Daphnia were calculated following their exposure to grazing by largebodied $D$. pulicaria and small-bodied $D$. longispina in 20,24 , and $28^{\circ} \mathrm{C}$. Rising temperature did not affect the
\end{abstract}

Guest editors: Adam Petrusek \& Piet Spaak / Proceedings of the 10th International Symposium on Cladocera

A. Sikora $(\bowtie) \cdot$ P. Dawidowicz

Department of Hydrobiology, Faculty of Biology,

Biological and Chemical Research Center, University of

Warsaw, Żwirki i Wigury 101, 02-089 Warsaw, Poland

e-mail: a.b.sikora@uw.edu.pl

P. Dawidowicz

e-mail: p.dawidowicz@uw.edu.pl intensity of breakage of $C$. raciborskii trichomes by $D$. pulicaria and caused decrease in clearance rate of this species, whereas for $D$. longispina, the temperature increase enhanced both filament breakage and clearance rate. We suggest that these temperature-related changes may affect relative competitive performance of Daphnia species in the presence of cyanobacteria.

Keywords Daphnia $\cdot$ Cyanobacteria $\cdot$ Filament length $\cdot$ Zooplankton $\cdot$ Body size $\cdot$ Temperature

\section{Introduction}

Cyanobacteria are known to be an inadequate source of food for Daphnia for a variety of reasons, including low nutritional value and a lack of essential compounds (especially polyunsaturated fatty acids and sterols). They are also difficult for Daphnia to consume due to their size and shape (Porter \& Orcutt, 1980; Lampert, 1987; von Elert \& Wolffrom, 2001). Moreover, some cyanobacterial species or strains produce toxins (Leflaive \& Ten-Hage, 2007). Cyanobacterial filaments and colonies can interfere with the food collection of daphnids by clogging their filtering apparatus, thus limiting Daphnia feeding efficiency. When cyanobacterial filaments are abundant, daphnids increase the frequency of rejection movements by their postabdominal claws (Gliwicz \& Siedlar, 1980; Kirk \& Gilbert, 1992). As a result, the presence of cyanobacterial filaments leads to higher 
rates of respiration as well as reduced rates of feeding and assimilation and may also cause egg abortion (Porter \& McDonough, 1984; Hawkins \& Lampert, 1989; DeBernardi \& Giussani, 1990; Gilbert \& Durand, 1990; Bednarska \& Slusarczyk, 2013). Nevertheless, Daphnia, like other zooplankton taxa such as copepods and rotifers, are able to break down cyanobacterial filaments into small particles, thereby improving their palatability (Dawidowicz, 1990; Bouvy et al., 2001; Gulati et al., 2001). It has been shown that short non-toxic cyanobacterial filaments cause lower reduction in the growth rate and fecundity of Daphnia in comparison with longer ones (Bednarska et al., 2014). Cyanobacterial filaments could, therefore, serve as a supplementary food for zooplankton herbivores, especially under food-limiting conditions (DeBernardi \& Giussani, 1990; Gilbert \& Durand, 1990).

Both water temperature and cladoceran body size may affect the interference with cyanobacterial filaments. At higher temperatures, decreased water viscosity increases the flow through the filter screens, which in turn leads to more intensive mechanical interference by cyanobacteria filaments with Daphnia filtering combs (Abrusán, 2004). Small-bodied cladocerans are known to be more resistant to such interference than large-sized species, because they have a relatively narrow gap in their carapace, which prevents filaments from entering the filtration chamber (Gliwicz \& Siedlar, 1980; Porter \& McDonough, 1984; Panosso \& Lürling, 2010). It has also been suggested that the food-gathering process is qualitatively different between Daphnia species which differ in body size, due to variation in the hydrodynamics of water flow through the filtering apparatus. Due to the lower values of the Reynolds number, the filtering combs of small-bodied species act more as paddles than sieves, which reduces clogging of the filters (Abrusán, 2004).

Additionally, in tropical and subtropical waters, high temperatures and selective grazing on other algae by some zooplankton taxa, e.g., copepods, promote cyanobacterial blooms (Hong et al., 2013), which results in small grazers (small-bodied cladocerans, copepods and rotifers) predominating in zooplankton communities; large cladocerans rarely occur there (Gillooly \& Dodson, 2000). Furthermore, in temperate lakes during the summer, when there is a relatively high abundance of cyanobacteria, small-bodied species dominate large-bodied ones, a phenomenon known as "midsummer decline" (Sommer et al., 1986; Müller-Navarra et al., 2000; Wagner et al., 2004).

We suggest that temperature-driven variations in cyanobacterial filament breakage and clearance rate may affect the competitive abilities of Daphnia species which differ in body size. An evaluation of the shortening of cyanobacterial filaments and the clearance rate was made by measuring the filament lengths of a non-toxic strain of Cylindrospermopsis raciborskii, which were exposed to grazing by two Daphnia species differing in body size, under various thermal conditions. The objective of the study was to test the hypothesis that shortening of cyanobacterial filaments, and the clearance rate would increase with rising temperature, due to increase the flow through the filter screens, for small-bodied Daphnia, but stay on the same level (or increase less) for large-bodied species that are more vulnerable to interference by cyanobacteria filaments.

\section{Materials and methods}

We carried out a laboratory feeding experiment using three clones of large-bodied D. pulicaria and three clones of small-bodied $D$. longispina. The origins and body sizes of the 4-day-old experimental Daphnia clones are presented in Table 1. We should mention that clones of $D$. pulicaria used in our experiments come from two genetically divergent clades: North American (clones DpBrA3, DpBrS) and European (clone DpBh; Colbourne et al., 1998). All of the clones had been maintained in the laboratory for many generations prior to the study. Prior to the experiment, the mothers from all the clones were maintained at experimental temperatures of 20,24 , and $28^{\circ} \mathrm{C}$ in 31 glass beakers containing lake water (filtered through a $0.45 \mu \mathrm{m}$ filter) under a summer light regime $(16: 8 \mathrm{~h}$ light:dark cycle, light: $20 \mu \mathrm{mol} \mathrm{m} \mathrm{m}^{-2} \mathrm{~s}^{-1}$ ). The lake water used in the experiment came from the small eutrophic Lake Szczęśliwice located in Warsaw, Poland, which had been filtered through a $1-\mu \mathrm{m}$ filter and stored in aerated tanks for at least 2 weeks prior to its use. The Daphnia were fed green alga (Scenedesmus obliquus, strain no. 72, University of Texas Collection Center, Austin, USA), which had been batch cultured at $20^{\circ} \mathrm{C}$ (light: $90-100 \mu \mathrm{mol} \mathrm{m}{ }^{-2} \mathrm{~s}^{-1}$ ) in aerated 2-1 flasks in Bold's basal medium 
Table 1 Origin and body size $(\mathrm{mm})$ of 4-day-old experimental Daphnia clones

\begin{tabular}{lllll}
\hline Species & Clones & Origin & Body size (mm) & SD (mm) \\
\hline D. longispina & Dl6 & Lake Roś, Poland & 0.94 & 0.13 \\
& Dl4 & Lake Roś, Poland & 1.13 & 0.16 \\
& DlE & Lake Roś, Poland & 1.14 & 0.11 \\
D. pulicaria & DpBh & Unknown Lake, Czech Republic & 1.43 & 0.24 \\
& DpBrA3 & Lake Brome, Canada & 1.27 & 0.16 \\
& DpBrS & Lake Brome, Canada & 1.31 & 0.14 \\
\hline
\end{tabular}

Data are means \pm 1 SD from 54 to 135 individuals

(Borowitzka \& Borowitzka, 1988). Four-day-old Daphnia from their clonal mothers' second clutch were used to begin the experiment. Prior to the beginning of the experiment, the animals were kept for $24 \mathrm{~h}$ in lake water without food suspensions in order to empty their guts. The experiment was carried out in 30-ml plastic beakers filled entirely with filtered $(0.2 \mu \mathrm{m})$ lake water containing C. raciborskii filaments (non-toxic strain no. 1.97, Sammlung von Algenkulturen, Univestität Göttingen, Germany), batch-cultured at $24^{\circ} \mathrm{C}$ (light: $40-50 \mu \mathrm{mol} \mathrm{m} \mathrm{m}^{-2} \mathrm{~s}^{-1}$ ) in aerated 1-1 flasks in Z-4 medium (Zehnder \& Gorham, 1960) at a density equivalent to $1 \mathrm{mg}$ organic $\mathrm{Cl}^{-1}$. Algal cells were harvested at late log phase, and the carbon concentration of the algal suspensions was estimated using photometric light extinction at $800 \mathrm{~nm}$, making use of previously established carbon-extinction regressions. The experiment was conducted in a thermostatic chamber in the dark, in three thermal treatments: 20,24 , and $28^{\circ} \mathrm{C}$. Additionally, control treatment without animals was also established. For each clone, we set up, respectively, three beakers containing 6 animals for D. pulicaria, and three beakers containing 15 animals for $D$. longispina. The experiment was carried out on a plankton wheel at $1 \mathrm{rpm}$ in order to prevent sedimentation of the cyanobacteria during the $6 \mathrm{~h}$ of the experiment. Following completion of the experiment, samples of cyanobacterial filaments were preserved in a mixture of Lugol's solution and formalin. We then calculated the number of filaments in a Fuchs-Rosenthal haemocytometer. We measured the length of all the filaments in randomly selected subsamples of $32 \mu \mathrm{l}$ under a dissection microscope using the video analysis software MultiScan 14.02 . Clearance rate $\left(\mathrm{ml}^{-1}\right.$ individual $^{-1} \mathrm{~h}^{-1}$ ) was based on the changes measured in cyanobacteria biovolume $\left(\mu \mathrm{m}^{3} \mathrm{ml}^{-1}\right)$ between the control and the experimental beakers according to the equation (Peters, 1984):
$C R=\frac{V \cdot\left(\ln B_{0}-\ln B_{t}\right)}{t \cdot N}$,

where $V$ is volume of the experimental beakers $(\mathrm{ml})$, $B_{0}$ is initial biovolume, $B_{t}$ is final biovolume, $t$ is length of the experiment (h), $N$ is number of animals in the experimental beakers.

We used an analysis of variance (ANOVA) test followed by the Tukey-HSD test for multiple comparisons to investigate the effects of temperature and species on the differences in clearance rate and mean length of the filaments. The factor 'clone' was nested within the species. Prior to the analysis, data for filament length and clearance rate were log-transformed. We used the Kolmogorov-Smirnov twosample test to check if the mean filament lengths of the samples had a divergent distribution. The mean filament lengths used in the analyses were divided into size class intervals of $30 \mu \mathrm{m}$. Both analyses were performed using Statistix 9.0 software.

\section{Results}

Reduction in the mean filament length was observed in both the D. longispina and D. pulicaria treatments. As indicated by the significant effect of the temperature * species interaction (ANOVA, $F=2.79, P=0.0366$ ), shortening of the filaments by both Daphnia species varied between the thermal treatments. Intensity of filament breakage for the large-bodied D. pulicaria was similar across the entire range of temperatures, whereas for the smaller-bodied $D$. longispina, this intensity increased with the rising temperature. At $20^{\circ} \mathrm{C}$, the mean filament length of the samples with $D$. longispina treatments $(321 \pm 45 \mu \mathrm{m})$ did not differ significantly from the control treatment ( $323 \pm 28 \mu \mathrm{m}$; Table 2), whereas it was significantly lower in the $D$. pulicaria treatments $(265 \pm 24 \mu \mathrm{m}$, Table 2$)$. The 
Table 2 Mean length $(\mu \mathrm{m})$ of cyanobacterial filaments Cylindrospermopsis raciborskii in three thermal regimes: 20,24 , and $28^{\circ} \mathrm{C}$

\begin{tabular}{llllll}
\hline Temperature & Species & Median & Mean & SD & Homogenous group \\
\hline $20^{\circ} \mathrm{C}$ & Control & 257 & 323 & 28 & A \\
& D. longispina & 253 & 321 & 45 & $\mathrm{~A}$ \\
& D. pulicaria & 211 & 265 & 24 & $\mathrm{~B}$ \\
$24^{\circ} \mathrm{C}$ & Control & 257 & 323 & 21 & $\mathrm{~A}$ \\
& D. longispina & 198 & 259 & 44 & $\mathrm{~B}$ \\
& D. pulicaria & 174 & 226 & 20 & $\mathrm{~B}$ \\
$28^{\circ} \mathrm{C}$ & Control & 262 & 326 & 33 & $\mathrm{~A}$ \\
& D. longispina & 207 & 256 & 26 & $\mathrm{~B}$ \\
& D. pulicaria & 198 & 252 & 35 & $\mathrm{~B}$ \\
\end{tabular}

Data are medians and means for three clones and three replicates for treatments with large-bodied D. pulicaria, small-bodied $D$. longispina, and control without any animals. Letters indicates homogenous groups between means of experimental treatments (Tukey-HSD test for multiple comparisons, $P<0.05$ )

frequency distribution of the mean filament lengths in both of the Daphnia treatments did not differ significantly from that of the control treatment (KolmogorovSmirnov Test, $P=1.0000$ for $D$. longispina and $P=0.2410$ for D. pulicaria; Fig. 1, Table 3). At 24 and $28^{\circ} \mathrm{C}$, both Daphnia species broke down the cyanobacterial filaments intensively, as was indicated by a statistically significant decrease in their mean filament lengths (Table 2) and a divergent (more rightskewed) frequency distribution for the cyanobacterial filaments compared to the control treatment (Kolmogorov-Smirnov Test, $P \leq 0.05$; Fig. 1, Table 3). At $24^{\circ} \mathrm{C}$, D. pulicaria treatments had an apparently lower mean cyanobacterial filament length than in treatments with D. longispina $(226 \pm 20$ and $259 \pm 44 \mu \mathrm{m}$, respectively), but this difference was not statistically significant (Table 2). At $28^{\circ} \mathrm{C}$, both species broke cyanobacterial filaments with a similar intensity, which was indicated by nearly the same mean length of filaments: $252 \pm 35$ and $256 \pm 26 \mu \mathrm{m}$ for the $D$. pulicaria and $D$. longispina treatments, respectively (Table 2).

Shortening of the cyanobacteria filaments varied significantly among the clones within both of the Daphnia species (species * clone interaction; ANOVA, $F=3.80, P=0.0097)$. Variation in the mean length of the cyanobacterial filaments, however, was observed only among the $D$. longispina clones (only clone D16 differed significantly from clone D14; clone DIE did not differed significantly from both of them), whereas D. pulicaria clones did not differ significantly.
The clearance rate for cyanobacteria of $D$. pulicaria was within the range of $0.38-0.64 \mathrm{ml}^{-1}$ ind. ${ }^{-1} \mathrm{~h}^{-1}$ and was higher than that of $D$. longispina: 0.06$0.15 \mathrm{ml}^{-1}$ ind. $^{-1} \mathrm{~h}^{-1}$ (ANOVA, $F=79.11, \quad P<$ 0.0001; Fig. 2). Similarly, as was the case for the shortening of the filaments, the clearance rate varied between thermal treatments in both species (temperature * species interaction; ANOVA, $F=4.06$, $P=0.0248$ ). With increasing temperature, the largebodied $D$. pulicaria decreased its clearance rate, whereas the small-bodied $D$. longispina showed an increased clearance rate (Fig. 2). No variation was observed among clones (species * clone interaction; ANOVA, $F=2.18, P=0.0886$ ).

\section{Discussion}

Both studied Daphnia species investigated in the study broke up filaments of the cyanobacterium $C$. raciborskii, but with different intensities dependent on temperature. At $20^{\circ} \mathrm{C}$, the effect of small-bodied $D$. longispina on mean cyanobacteria filament length was negligible, while $D$. pulicaria shortened the filaments significantly. Breakage of the cyanobacterial filaments remained unchanged for the large-bodied $D$. pulicaria across the range of temperatures tested, whereas for the small-bodied D. longispina, it increased. Similarly, as the temperature increased, the clearance rate for D. pulicaria decreased, whereas for D. longispina, the clearance rate increased. Consequently, the difference between the two species tended to decrease with 
Fig. 1 Frequency

distribution of

cyanobacterial filaments in treatment with $D$. pulicaria (grey bar), D. longispina (white bar), and control treatment without animals (black bar) in thermal treatment a $20^{\circ} \mathrm{C}, \mathbf{b} 24^{\circ} \mathrm{C}$, and $\mathbf{c} 28^{\circ} \mathrm{C}$

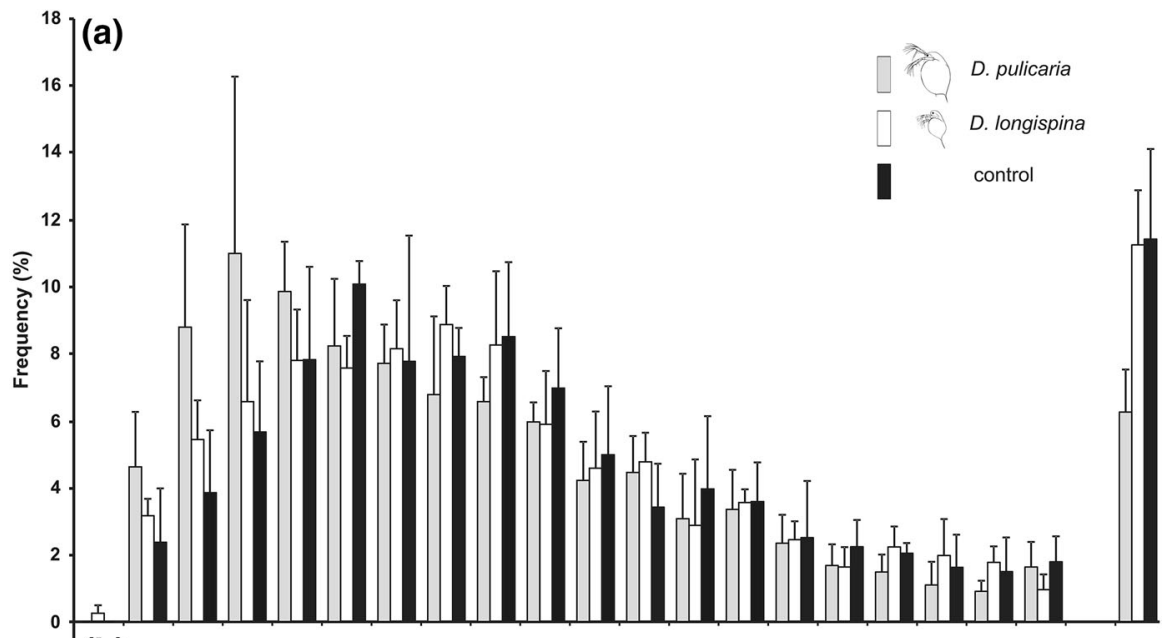

(b)

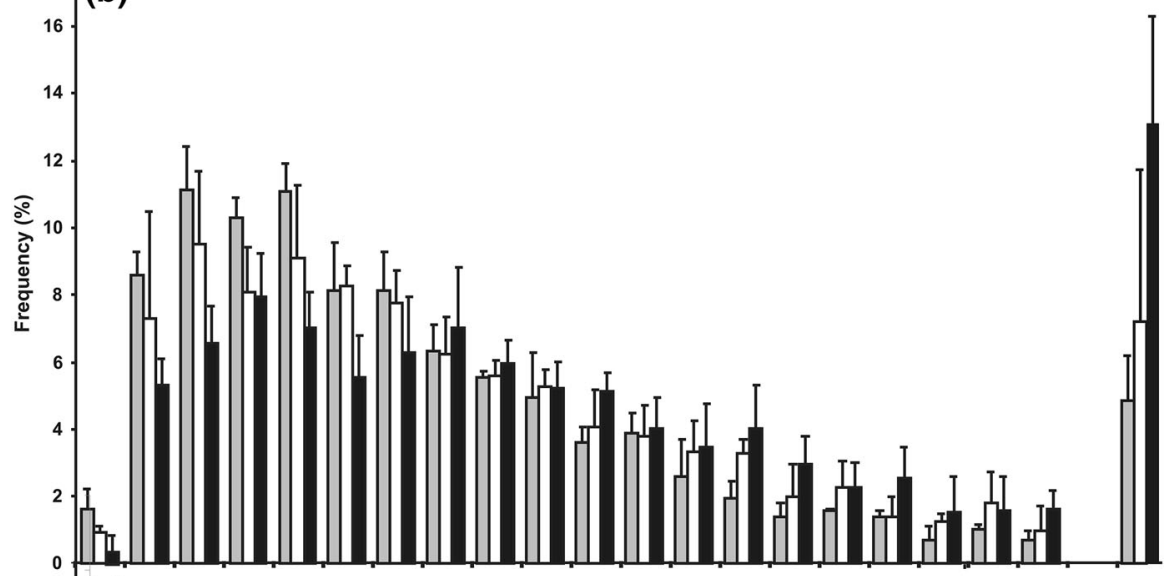

(c)

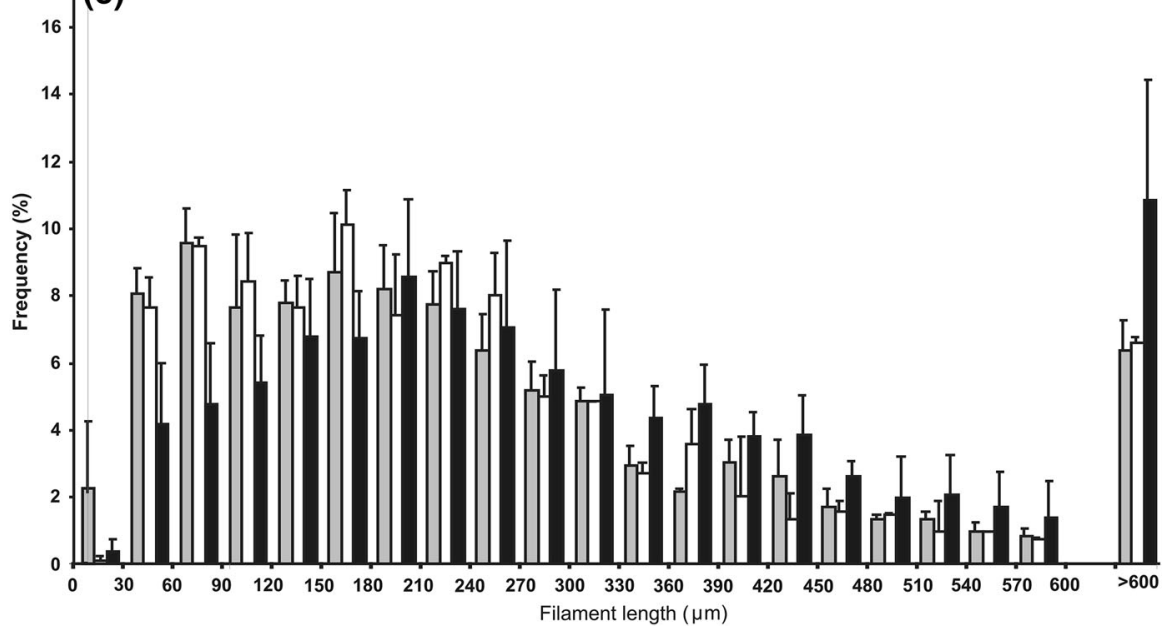

exposure to increasing water temperature. At $28^{\circ} \mathrm{C}$, the reduction in cyanobacterial filament length was nearly identical for both Daphnia species, but the clearance rate for cyanobacteria was still 2.5 times higher for $D$. pulicaria. We have observed only little variation among clones of both Daphnia species. 
Table 3 Results of the Kolmogorov-Smirnov two-sample test comparing distribution of cyanobacterial filaments (Cylindrospermopsis raciborskii) length in treatment with largebodied $D$. pulicaria and small-bodied $D$. longispina to the control treatment without any animals in three thermal regimes: 20,24 , and $28^{\circ} \mathrm{C}$

\begin{tabular}{lllr}
\hline Temperature & Treatment & $Z$ & \multicolumn{2}{l}{$P$} \\
\hline $20^{\circ} \mathrm{C}$ & D. longispina vs control & 0.06 & 1.0000 \\
& D. pulicaria vs control & 0.15 & 0.2410 \\
$24^{\circ} \mathrm{C}$ & D. longispina vs control & 0.14 & $\mathbf{0 . 0 0 8 4}$ \\
& D. pulicaria vs control & 0.21 & $<\mathbf{0 . 0 0 0 1}$ \\
$28^{\circ} \mathrm{C}$ & D. longispina vs Control & 0.17 & $\mathbf{0 . 0 0 6 3}$ \\
& D. pulicaria vs Control & 0.18 & $\mathbf{0 . 0 0 1 7}$ \\
\hline
\end{tabular}

Significant results are emphasized in bold letters $(P<0.05)$

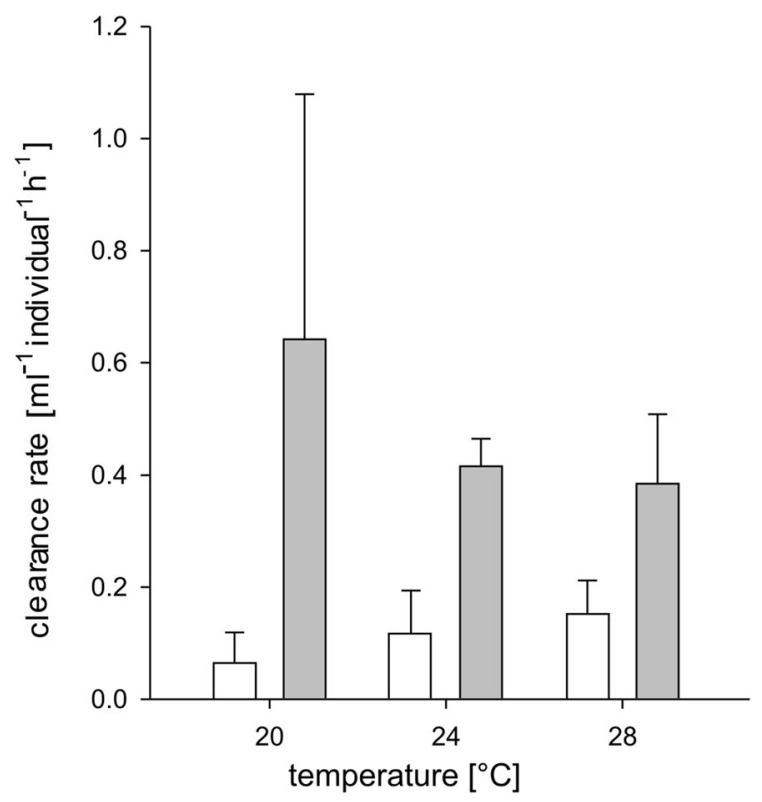

Fig. 2 Clearance rate $\left(\mathrm{ml}^{-1}\right.$ individual $\left.{ }^{-1} \mathrm{~h}^{-1}\right)$ in three thermal treatments: 20,24 , and $28^{\circ} \mathrm{C}$. Data are means $\pm 1 \mathrm{SD}$ for three clones and three replicates for D. pulicaria (grey bar) and $D$. longispina (white bar)

Although D. pulicaria clones come from two genetically divergent clades (Colbourne et al., 1998), we have not found statistically significant differences in shortening of cyanobacteria filaments as well as clearance rate.

The observed decreases in the mean lengths of cyanobacterial filaments could have contributed to the increase in ingestion rate of filaments by Daphnia, which generally prefer smaller-sized food particles within the range of 2-50 $\mu \mathrm{m}$ (Geller \& Müller, 1981;
Sommer, 1988). A propensity to consume cyanobacterial filaments has been previously reported for a number of Daphnia species (Dawidowicz, 1990; Gilbert \& Durand, 1990; Kurmayer, 2001; Reichwaldt \& Abrusán, 2007). As demonstrated experimentally, another large-bodied Daphnia species, D. magna, was able to control the population growth of filamentous cyanobacteria (at a temperature of $20^{\circ} \mathrm{C}$ ) as long as the density of the cyanobacteria remained low (Dawidowicz et al., 1988). Breakage of cyanobacterial trichomes was suggested as an important mechanism allowing Daphnia to maintain such population control (Dawidowicz, 1990). If we can generalize about our observations of $D$. pulicaria, one could expect a relative decrease in the efficiency of filamentous cyanobacteria breakage by large-bodied daphnids at elevated temperatures. In addition, it has been found that cyanobacterial filaments of Aphanizomenon gracile decrease in length in the presence of Daphnia infochemicals (Cerbin et al., 2013). Considering that cyanobacteria population growth increases with rising temperatures, and that some of the morphological characteristics of cyanobacterial trichomes change with increasing temperature (e.g., trichomes were shorter and wider; Soares et al., 2013), these changes would not be followed by an increase in filament processing and utilization by large-bodied Daphnia. The lack of positive effect of temperature on filament shortening and the decreasing cyanobacteria clearance rate by $D$. pulicaria could be explained by the susceptibility of this large-bodied species to mechanical interference.

On the other hand, filament breakage increased in the smaller D. longispina with increasing temperature, along with an increase in clearance rate for the cyanobacteria. Such an adaptation may allow $D$. longispina to graze on filaments more efficiently as the water warms up. Consequently, the relative performance of the small-bodied Daphnia species may increase, which would mitigate, but not reverse, the competitive superiority of the larger D. pulicaria. It has been suggested that the mere presence of cyanobacteria cannot reverse the competitive advantage of the larger-bodied species over the smallerbodied ones (Kurmayer, 2001), even at higher temperatures (Sikora \& Dawidowicz, 2014). Yet it is probable that the superior utilization of cyanobacterial filaments by small-bodied zooplankton compared to their larger-bodied congeners (Gulati et al., 2001) 
contributes, along with other factors, not tested in the experiment: e.g., toxicity of cyanobacteria (Jiang et al., 2014a, b) or fish predation (Havens et al., 2015), to the dominance of small-bodied species in tropical and subtropical lakes and in temperate lakes during the "midsummer decline." Such investigation of the interactions between Daphnia and cyanobacteria should be factored into the prediction of the potential effects of climate change on temperate lakes.

\section{Conclusion}

The results of our study show that small-sized Daphnia increase the intensity of filament' breakage and the clearance rate for cyanobacteria with rising water temperature more than in the large-bodied species. Better utilization of cyanobacterial filaments with increasing temperature by small-bodied zooplankton could be, together with other factors, responsible for the observed dominance of smallbodied cladoceran species in warm-water lakes, where cyanobacteria are frequently the major food source for filter-feeding zooplankton.

Acknowledgments We are grateful to Paweł Koperski for his great help and for the valuable comments he made on the manuscript, and also to Tomasz Karasek and Jacek Radzikowski for their assistance in the laboratory. We would like to thank Adam Petrusek, as well as two anonymous referees for the comments and suggestions on earlier versions of the manuscript. Financial support by grant N N305 134440 was from the Polish Ministry of Science and Higher Education to Piotr Dawidowicz.

Open Access This article is distributed under the terms of the Creative Commons Attribution 4.0 International License (http:// creativecommons.org/licenses/by/4.0/), which permits unrestricted use, distribution, and reproduction in any medium, provided you give appropriate credit to the original author(s) and the source, provide a link to the Creative Commons license, and indicate if changes were made.

\section{References}

Abrusán, G., 2004. Filamentous cyanobacteria, temperature and Daphnia growth: the role of fluid mechanics. Oecologia 141: 395-401.

Bednarska, A. \& M. Slusarczyk, 2013. Effect of non-toxic, filamentous cyanobacteria on egg abortion in Daphnia under various thermal conditions. Hydrobiologia 715: 151-157.
Borowitzka, M. A. \& L. J. Borowitzka, 1988. Micro-algal biotechnology. Cambridge University Press, London.

Bednarska, A., B. Pietrzak \& J. Pijanowska, 2014. Effect of poor manageability and low nutritional value of cyanobacteria on Daphnia magna life history performance. Journal of Plankton Research 36: 838-847.

Bouvy, M., M. Pagano \& M. Troussellier, 2001. Effects of a cyanobacterial bloom (Cylindrospermopsis raciborskii) on bacteria and zooplankton communities in Ingazeira reservoir (northeast Brazil). Aquatic Microbial Ecology 25: 215-227.

Cerbin, S., Ł. Wejnerowski \& M. Dziuba, 2013. Aphanizomenon gracile increases in with in the presence of Daphnia. A defence mechanism against grazing? Journal of Limnology 72: 505-511.

Colbourne, J. K., T. J. Crease, L. J. Weider, P. D. N. Herbert, F. Dufresne \& A. Hobæk, 1998. Phylogenetics and evolution of a circumarctic species complex (Cladocera: Daphnia pulex). Biological Journal of the Linnean Society 65: 347-365.

Dawidowicz, P., 1990. The effect of Daphnia on filament length of blue-green algae. Hydrobiologia 191: 265-268.

Dawidowicz, P., Z. M. Gliwicz \& R. D. Gulami, 1988. Can Daphnia magna prevent a blue-green algal bloom in hypertrophic lake? A laboratory test. Limnologica (Berlin) 19: 21-26.

DeBernardi, R. \& G. Giussani, 1990. Are blue-green algae a suitable food for zooplankton? An overview. Hydrobiologia 200(201): 29-41.

Geller, W. \& H. Müller, 1981. The filtration apparatus of Cladocera: filter mesh-sizes and their implications on food selectivity. Oecologia (Berlin) 49: 316-321.

Gilbert, J. J. \& M. W. Durand, 1990. Effect of Anabena flosaquae on the abilities of Daphnia and Keratella to feed and reproduce on unicellular algae. Freshwater Biology 24: 577-596.

Gillooly, J. F. \& S. I. Dodson, 2000. Latitudinal patterns in the size distribution and seasonal dynamics of new world, freshwater cladocerans. Limnology and Oceanography 45: 22-30.

Gliwicz, Z. M. \& E. Siedlar, 1980. Food size limitation and algae interfering with food collection in Daphnia. Archiv für Hydrobiologie 88: 155-177.

Gulati, R. D., M. Bronkhorts \& E. van Donk, 2001. Feeding in Daphnia galeata on Oscillatoria limnetica and on detritus derived from it. Journal of Plankton Research 23: 705-718.

Havens, K. E., J. R. Beaver, E. E. Manis \& T. L. East, 2015. Inter-lake comparisons indicate that fish predation, rather than high temperature, is the major driver of summer decline in Daphnia and other changes among cladoceran zooplankton in subtropical Florida lakes. Hydrobiologia 750: $57-67$.

Hawkins, P. \& W. Lampert, 1989. The effect of Daphnia body size on filtering rate inhibition in the presence of a filamentous cyanobacterium. Limnology and Oceanography 34: 1084-1089.

Hong, Y., M. A. Burford, P. J. Ralph, J. W. Udy \& M. A. Doblin, 2013. The cyanobacterium Cylindrospermopsis raciborskii is facilitated by copepod selective grazing. Harmful algae 29: 14-21. 
Jiang, X., W. Yang, X. Xiang, Y. Niu, L. Chen \& J. Zhang, 2014a. Cyanobacteria alter competitive outcomes between Daphnia and Bosmina in dependence on environmental conditions. Fundamental and Applied Limnology 184: $11-22$.

Jiang, X., W. Yang, L. Zhang, L. Chen \& Y. Niu, 2014b. Predation and cyanobacteria jointly facilitate competitive dominance of small-bodied cladocerans. Journal of Plankton Research 36: 956-965.

Kirk, K. L. \& J. T. Gilbert, 1992. Variation in herbivore response to chemical defenses: zooplankton foraging on toxic cyanobacteria. Ecology 73: 2208-2217.

Kurmayer, R., 2001. Competitive ability of Daphnia under dominance of non-toxic filamentous cyanobacteria. Hydrobiologia 442: 279-289.

Lampert, W., 1987. Laboratory studies on zooplanktoncyanobacteria interactions. New Zealand Journal of Marine and Freshwater Research 21: 483-490.

Leflaive, J. \& L. Ten-Hage, 2007. Algal and cyanobacterial secondary metabolites in freshwaters: a comparison of allelopathis compounds and toxins. Freshwater Biology 52: 199-214.

Müller-Navarra, D. C., M. T. Brett, A. M. Liston \& C. R. Goldman, 2000. A highly unsaturated fatty acid predicts carbon transfer between primary producers and consumers. Nature 403: 74-77.

Panosso, R. \& M. F. L. L. Lürling, 2010. Daphnia magna feeding on Cylindrospermopsis raciborskii: the role of food composition, filament length and body size. Journal of Plankton Research 32: 1393-1404.

Peters, R. H., 1984. Methods for the study of feeding, grazing and assimilation by zooplankton. A manual on methods for the assessment of secondary productivity in fresh waters. 2nd ed. IBP Handbook 17: 336-412.

Porter, K. G. \& R. McDonough, 1984. The energetic cost of response to blue-green algal filaments by cladocerans. Limnology and Oceanography 29: 365-369.

Porter, K. G. \& J. D. Orcutt, 1980. Nutritional adequacy, manageability, and toxicity as factors that determine the food quality of green and blue-green algae for Daphnia. In Kerfoot, W. C. (ed.), Evolution and ecology of zooplankton communities. University Press of New England, Lebanon: 268-281.

Reichwaldt, E. S. \& G. Abrusán, 2007. Influence of food quality on depth selection of Daphnia pulicaria. Journal of Plankton Research 29: 839-849.

Sikora, A. \& P. Dawidowicz, 2014. Do the presence of filamentous cyanobacteria and an elevated temperature favor small-bodied Daphnia in interspecific competitive interactions? Fundamental and Applied Limnology 185: 307-314.

Soares, M. C. S., M. Lürling \& V. Huszar, 2013. Growth and temperature-related phenotypic plasticity in the cyanobacterium Cylindrospermopsis raciborskii. Phycological Research 61: 61-67.

Sommer, U., 1988. Phytoplankton succession in microcosm experiments under simultaneous grazing pressure and resource limitation. Limnology and Oceanography 33: 1037-1054.

Sommer, U., Z. M. Gliwicz, W. Lampert \& A. Duncan, 1986. The PEF-model of seasonal succession of planktonic events in fresh waters. Archiv für Hydrobiologie 106: 433-471.

von Elert, E. \& T. Wolffrom, 2001. Supplementation of cyanobacterial food with polyunsaturated fatty acids does not improve growth of Daphnia. Limnology and Oceanography 46: 1552-1558.

Wagner, A., S. Hülsmann, H. Dörner, M. Janssen, U. Kahl, T. Mehner \& J. Benndorf, 2004. Initiation of the midsummer decline of Daphnia as related to predation, non-consumptive mortality and recruitment: a balance. Archiv für Hydrobiologie 160: 1-23.

Zehnder, A. A. \& P. R. Gorham, 1960. Factor influencing the growth of Microcystis aeruginosa Kütz. emend. Elenkin. Canadian Journal of Microbiology 6: 645-660. 